TABIE II.-Distribution of the Staphylococcal Strains Within the Different Phage Groups

\begin{tabular}{|c|c|c|c|c|c|c|c|c|}
\hline \multirow{2}{*}{$\begin{array}{c}\text { Site } \\
\text { of } \\
\text { Carriage }\end{array}$} & \multirow{2}{*}{$\begin{array}{c}\text { No. } \\
\text { of } \\
\text { Strains }\end{array}$} & \multicolumn{6}{|c|}{ Phage Groups } & \multirow{2}{*}{$\begin{array}{c}\text { Not } \\
\text { Typable } \\
\text { Strains }\end{array}$} \\
\hline & & I & II & III & IV & $\mathrm{V}$ & Misc. & \\
\hline $\begin{array}{l}\text { Pos. only } \\
\underset{\mathbf{T}}{\mathbf{P}} \\
\mathbf{P}\end{array}$ & $\begin{array}{r}412 \\
363 \\
90\end{array}$ & $\begin{array}{r}157 \\
106 \\
26\end{array}$ & $\begin{array}{r}50 \\
31 \\
9\end{array}$ & $\begin{array}{l}68 \\
78 \\
18\end{array}$ & $\begin{array}{r}1 \\
12 \\
0\end{array}$ & $\begin{array}{r}30 \\
11 \\
2\end{array}$ & $\begin{array}{l}49 \\
70 \\
12\end{array}$ & $\begin{array}{l}57 \\
55 \\
23 \\
\end{array}$ \\
\hline $\begin{array}{l}\text { Pos. N } \\
\text { and T }\end{array}$ & $\begin{array}{l}467 \\
470\end{array}$ & $\begin{array}{l}168 \\
162\end{array}$ & $\begin{array}{l}53 \\
57\end{array}$ & $\begin{array}{l}89 \\
90\end{array}$ & $\begin{array}{l}6 \\
7\end{array}$ & $\begin{array}{l}39 \\
25\end{array}$ & $\begin{array}{l}64 \\
81\end{array}$ & $\begin{array}{l}48 \\
48\end{array}$ \\
\hline $\begin{array}{l}\text { Pos. N } \\
\text { and } \mathbf{P}\end{array}$ & $\begin{array}{l}111 \\
111\end{array}$ & $\begin{array}{l}30 \\
26\end{array}$ & $\begin{array}{r}12 \\
8\end{array}$ & $\begin{array}{l}24 \\
24\end{array}$ & $\begin{array}{l}0 \\
1\end{array}$ & $\begin{array}{l}7 \\
4\end{array}$ & $\begin{array}{l}21 \\
24\end{array}$ & $\begin{array}{l}17 \\
24\end{array}$ \\
\hline $\begin{array}{l}\begin{array}{c}\text { Pos. } T \\
\text { and } P\end{array} \\
\end{array}$ & $\begin{array}{l}48 \\
48\end{array}$ & $\begin{array}{l}19 \\
12 \\
\end{array}$ & $\frac{1}{2}$ & $\begin{array}{r}8 \\
13 \\
\end{array}$ & $\begin{array}{l}1 \\
0\end{array}$ & $\begin{array}{l}4 \\
1 \\
\end{array}$ & $\begin{array}{r}11 \\
8 \\
\end{array}$ & 12 \\
\hline $\begin{array}{l}\text { Pos. } \mathrm{N} \\
\text { and } \mathrm{T} \\
\text { and } \mathrm{P}\end{array}$ & $\begin{array}{l}200 \\
200 \\
200\end{array}$ & $\begin{array}{l}59 \\
57 \\
54\end{array}$ & $\begin{array}{l}23 \\
20 \\
26\end{array}$ & $\begin{array}{l}43 \\
52 \\
46\end{array}$ & $\begin{array}{l}2 \\
2 \\
1\end{array}$ & $\begin{array}{r}13 \\
8 \\
7\end{array}$ & $\begin{array}{l}37 \\
36 \\
41\end{array}$ & $\begin{array}{l}23 \\
25 \\
25\end{array}$ \\
\hline Total $\left\{\begin{array}{l}\text { No. } \\
\%\end{array}\right.$ & $\begin{array}{r}2,720 \\
100\end{array}$ & $\begin{array}{c}876 \\
32 \cdot 2\end{array}$ & $\begin{array}{c}292 \\
10.7\end{array}$ & $\begin{array}{c}553 \\
20 \cdot 3\end{array}$ & $\begin{array}{c}33 \\
1.2\end{array}$ & $\begin{array}{c}151 \\
5.6\end{array}$ & $\begin{array}{c}454 \\
16 \cdot 7\end{array}$ & $\begin{array}{l}361 \\
13.3\end{array}$ \\
\hline
\end{tabular}

$\mathrm{N}=$ Nose. $\mathrm{T}=$ Throat. $\mathrm{P}=$ Perineum. Misc. $=$ Miscellaneous.

patients examined had pathogenic staphylococci isolated from their perineum, either in the perineum alone or most often combined with carriage in other sites.

Staphylococci are often isolated from the faeces (Buttiaux and Pierret, 1949 ; Martyn, 1949 ; Brodie et al., 1956 ; Matthias et al., 1957 ; Hofstad and Wormnes, 1961) and less often from the vagina (Buttiaux and Pierret, 1949). In the present investigation samples from the faeces and vagina were not obtained. The perineal area may probably in some cases have been contaminated by staphylococci from these sites. But the equal distribution of perineal carriers between the two sexes in this investigation suggests that contamination of the perineal area from the vagina was of minor importance.

Our figures must be regarded as minimum figures. Nearly all of the persons examined had had a bath within an hour before the perineal swabs were obtained. Ridley (1959) has shown that washing (more thoroughly in his investigation than an ordinary bath) reduces the number of staphylococci in the perineum. On account of his work it is suggested that staphylococci persisting in the perineum after washing should be present in fairly abundant numbers before washing, and accordingly the perineal area may be a real breeding-place for these organisms and a potential source of infection. A patient whose perineum is a breeding-place for staphylococci is probably more apt to contaminate his bedding than most of the nasal carriers, and by indirect routes he may represent a dangerous source of infection. Investigations by Ridley (1959) and Hare (1963) point in this direction. Studies of the quantitative aspects of staphylococcal carriage by one of us (Solberg, 1964) show that perineal carriers may be heavy dispersers of staphylococci, even heavier than most of the nasal carriers.

It is therefore likely that individuals, especially patients, who are perineal carriers of pathogenic staphylococci represent a relatively greater danger than one should suspect from the relatively low incidence of such carriers.

\section{Summary}

A total of 3,508 patients admitted to a medical department were examined for perineal carriage of pathogenic staphylococci: $13 \%$ had these organisms in the perineum, either in the perineum alone or combined with other sites, and $2.6 \%$ had staphylococci only in the perineum.

As patients with perineal carriage easily contaminate their bedclothes, they can more easily than other carriers become heavy dispersers. Perineal carriers may therefore be a greater problem in the handling of hospital infection than is expressed by their incidence. Quantitative studies to be reported point in this direction.

\section{REFERENCES}

Brodie, J., Kerr, M. R., and Sommerville, T. (1956). Lancet, 1, 19. Buttiaux, R., and Pierret, J. (1949). Ann. Inst. Pasteur, 76, 480.

Gillespie, W. A., Simpson, K., and Tozer, R. C. (1958). Lancet, 2, 1075. Hare, R (1963), In Infection in Hospitals, edited by R. E. O.'Williams and R. A. Shooter, p. 75. Blackwell, Oxford. and Ridley, M. (1958). Brit. med. Y., 1, 69.

Hofstad, T., and Vogelsang, Th.M. (1960). Acta path. microbiol. scand., 48,155 .

- and Wormnes, A. (1961). Ibid., 51, 275.

Martyn, G. (1949). Brit. med. 7., 1, 710 .

Matthias, J. Q., Shooter, R. A., and Williams, R. E. O. (1957). Lancet, 1,1172 .

Ridley, M. (1959). Brit. med. 7., 1, 270.

Solberg, C. O. (1964). In preparation.

Tulloch, L. G., Alder, V. G., and Gillespie, W. A. (1960). Brit. med. 7., 2,354 .

\title{
Treatment of Rheumatic Fever: Comparison of Effects of Aspirin and Phenylbutazone
}

\author{
G. WILL, M.B., CH.B., B.SC., M.R.C.P.ED., M.R.C.P.GLAS. ; W. R. MURDOCH, M.B., CH.B., M.R.C.P., M.R.C.P.ED., M.R.C.P.GLAS.
}

Recent advances in the management of rheumatic fever have been mainly in the field of prevention. Salicylates were the standard treatment until the introduction of steroid and A.C.T.H. therapy. The Joint Report of the M.R.C. and American Heart Association (1955) on the treatment of acute rheumatic fever in children failed, however, to demonstrate that either of these new treatments was superior to salicylates alone. The earlier favourite experience of one of us with phenylbutazone (Fleming and Will, 1953 ; Will, 1958) led us to make a fuller study comparing the effects of salicylates and phenylbutazone.

\section{Clinical Methods}

This series comprises 88 patients investigated and treated by one or both of us in the following hospitals: Glasgow Royal Infirmary ; Eastern District Hospital, Glasgow ; Greenock Royal Infirmary ; and Dumfries and Galloway Royal Infirmary. All cases fulfilled the modified Ducket Jones (1944) diagnostic criteria used in the Joint Report of the M.R.C. and American Heart Association (1955). In every case the E.S.R., E.C.G., $x$-ray examination of chest, throat swabs, and antistreptolysin $\mathrm{O}$ (ASO) titres were carried out routinely. The E.S.R. was 
measured by the method of Westergren, and a fall of $15 \mathrm{~mm}$. in the first hour was taken as the upper limit of normal. In 24 cases serial plasma fibrogen readings were made, using the method of Stirland (1956). So far as was possible, alternate cases were treated with aspirin and phenylbutazone, although this was occasionally difficult as the centres were some distance apart. This explains the difference in numbers between the two groups. No selection of treatment was made on the basis of clinical severity. The age and sex distribution of the two series is shown in Table I. It has been suggested that acute carditis is more common in the under twenties (Begg et al., 1962), and it will be seen that there is a predominance of young cases in the phenylbutazone group. Both groups were compared in respect of the proportion of early cases, first attacks, carditis, E.C.G. abnormalities, ASO titres, and skin lesions. These results are summarized in Table II. The degree of correspondence of these figures would suggest that the two groups were of comparable severity.

\begin{tabular}{c|c|c|c|c|c|c}
\multicolumn{9}{c}{ TABLE I.-Age and Sex Distribution } \\
\hline \multirow{2}{*}{\begin{tabular}{c|c|c|c|c} 
Age in \\
Years
\end{tabular}} & \multicolumn{3}{|c|}{ Salicylate Group } & \multicolumn{2}{|c}{ Phenylbutazone Group } \\
\cline { 2 - 6 } \cline { 5 - 7 } & Males & Females & Total & Males & Females & Total \\
\hline $10-19$ & 8 & 6 & 14 & 18 & 14 & 32 \\
$20-29$ & 7 & 7 & 14 & 3 & 1 & 4 \\
$30-39$ & 4 & 4 & 8 & 4 & 1 & 5 \\
$40-49$ & 2 & 2 & 4 & 0 & 2 & 2 \\
$50-59$ & 0 & 1 & 1 & 3 & 1 & 4 \\
\hline Total & 21 & 20 & 41 & 28 & 19 & 47
\end{tabular}

\begin{tabular}{|c|c|c|c|}
\hline & & $\begin{array}{l}\text { Salicylate } \\
\text { Group (\%) }\end{array}$ & $\begin{array}{l}\text { Phenylbutazone } \\
\text { Group }(\%)\end{array}$ \\
\hline $\begin{array}{l}\text { Pirst attacks } \\
\text { Early (0-14 days) cases } \\
\text { Established heart lesions } \\
\text { Evidence of active carditis } \\
\text { E.C.G. abnormalities } \\
\text { Raised ASO titre .. } \\
\text { Skin manifestations }\end{array}$ & $\begin{array}{l}\cdots \\
\cdots \\
\cdots \\
\cdots \\
\cdots\end{array}$ & $\begin{array}{l}63 \cdot 4 \\
87 \cdot 8 \\
19 \cdot 5 \\
36 \cdot 6 \\
31 \cdot 7 \\
87 \\
14 \cdot 6\end{array}$ & $\begin{array}{l}59 \cdot 6 \\
85 \cdot 1 \\
17 \\
36 \cdot 1 \\
34 \\
77 \\
14 \cdot 9\end{array}$ \\
\hline
\end{tabular}

In the aspirin group all cases were given the dosage schedule of acetylsalicylic acid described in the Joint Report of the M.R.C. and American Heart Association (1955). Blood salicylate levels were carried out where necessary to assess the adequacy of absorption, a blood level of $30 \mathrm{mg} . / 100 \mathrm{ml}$. or over being considered satisfactory. A standard course of phenylbutazone consisted of $200 \mathrm{mg}$. thrice daily for four days, then $200 \mathrm{mg}$. twice daily for two weeks, followed by $200 \mathrm{mg}$. daily for at least a further two weeks. Both groups were treated with oral penicillin to prevent further streptococcal infection. Bed rest was maintained in all patients for a minimum period of six weeks. No antirheumatic drugs other than aspirin or phenylbutazone were used.

\section{Results}

The results were assessed clinically by the time taken for relief of joint pain and swelling and for resolution of fever and tachycardia. The duration of elevation of the E.S.R. was also noted.

Of the 41 patients in the aspirin group, four were afebrile throughout. In the remainder, fever had fallen within 48 hours in 14 and within seven days in $29(78.4 \%)$, but persisted for more than two weeks in four cases. Joint pain had settled in 48 hours in 10 , and within seven days in $36(87.8 \%)$. Tachycardia had resolved within 48 hours in two and within seven days in $16(42.1 \%)$. The pulse rate remained elevated for more than three weeks in seven. Three cases had no tachycardia throughout. The E.S.R. had fallen below $15 \mathrm{~mm}$. in one hour within four weeks in 24. A further 12 settled within the next four weeks, but in two cases remained elevated for more than 12 weeks. Of the 13 patients with E.C.G. abnormalities, these had returned to normal in seven by the end of the second week.

In the phenylbutazone group of 47 patients fever had fallen to normal within 48 hours in 29 and within seven days in 45 $(100 \%)$. Two patients were afebrile throughout. Joint pain had settled within 48 hours in 34 and within seven days in $47(100 \%)$. Tachycardia had resolved within 48 hours in 18 and within seven days in $40(85.1 \%)$. The pulse rate remained elevated for more than three weeks in only one patient. The E.S.R. had fallen to $15 \mathrm{~mm}$. in one hour within four weeks in 39 and had become normal in all 47 cases by the end of the sixth week. Of the 16 patients with E.C.G. abnormalities, these had returned to normal in 12 by the end of the second week.

Figs. 1, 2, and 3 show the results of treatment on fever, joint pain, and tachycardia in the two groups. The greater effectiveness of phenylbutazone is evident. These clinical findings are paralleled by the changes in the E.S.R., which are shown in Fig. 4. Whereas in the phenylbutazone group the E.S.R. had returned to normal in all cases by the end of six weeks, it was still elevated at this time in $22 \%$ of the aspirin-treated cases. During the treatment fresh acute manifestations occurred in seven of the patients on aspirin. One patient developed pericarditis on the sixteenth day of treatment. Two patients developed erythema marginatum and acute joint pain and swelling during the second week. In the remaining four there was recurrence of joint pain and swelling, which in three cases was accompanied by fever. In the phenylbutazone group no fresh acute manifestations occurred.

It was felt that the differences in age structure between the treatment groups might explain some of these results, as there is a general clinical impression that young people with rheumatic fever tend to respond more quickly than older people to anti-inflammatory drugs. To test this point, the groups
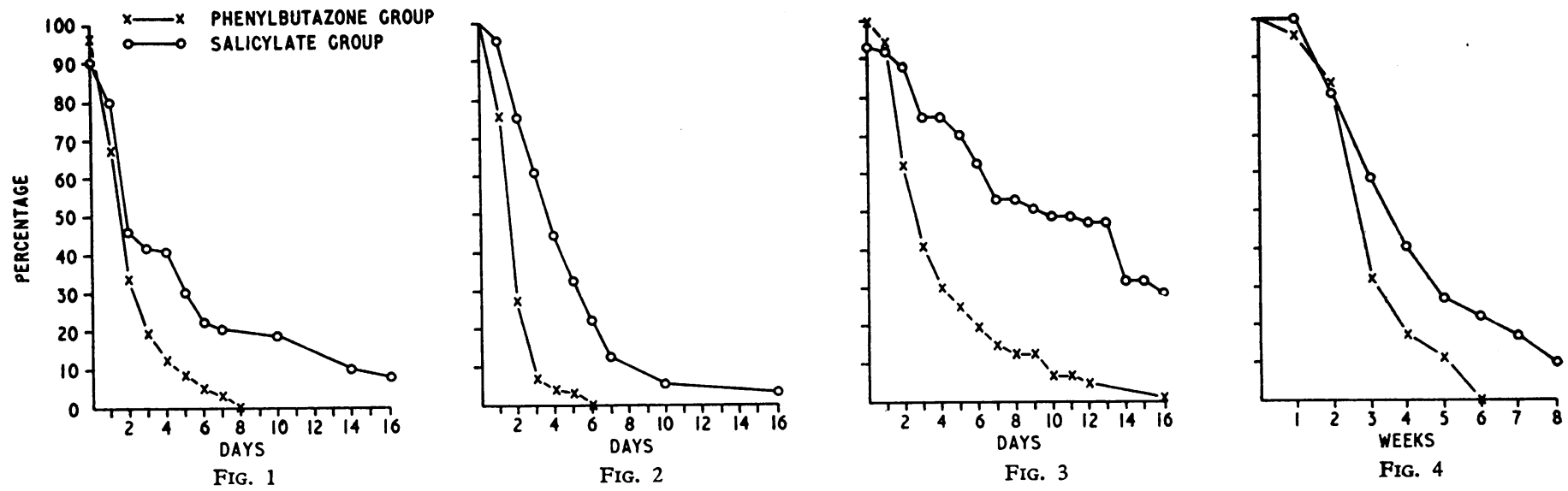

Figs. 1-4.-Proportion of cases in each group with fever (Fig. 1), joint pain (Fig. 2), tachycardia (Fig. 3), and raised E.S.R. (Fig. 4) graphed against time. 
were subdivided into ages $10-19$ and $20+$ and the results of treatment on fever, joint pains, tachycardia, and E.S.R. reassessed. The findings are presented in Figs. 5 to 8 , where the greater effectiveness of phenylbutazone in both age-groups is evident. The response of the treatment groups thus would not appear to have been determined by the different age structures.
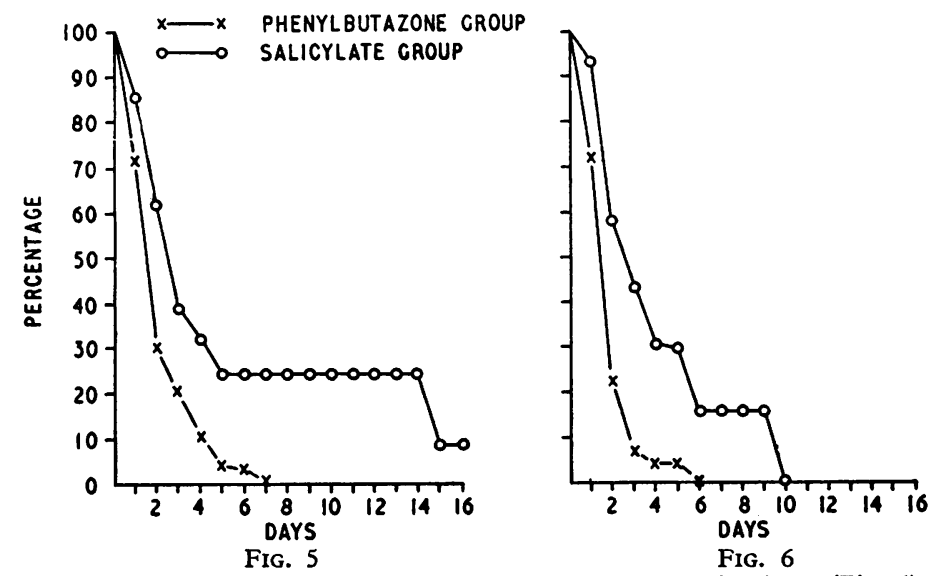

Figs. 5-8.-Proportion of cases in 10-19 age groups with fever (Fig. 5), pain against time.

1957). It seemed logical to us to carry out a trial comparing phenylbutazone with standard salicylate therapy. Our results have shown that the acute manifestations of the diseasenamely, fever, tachycardia, and joint pain-are more rapidly and completely suppressed by phenylbutazone than by aspirin. Phenylbutazone also produced a more rapid fall in the E.S.R.,
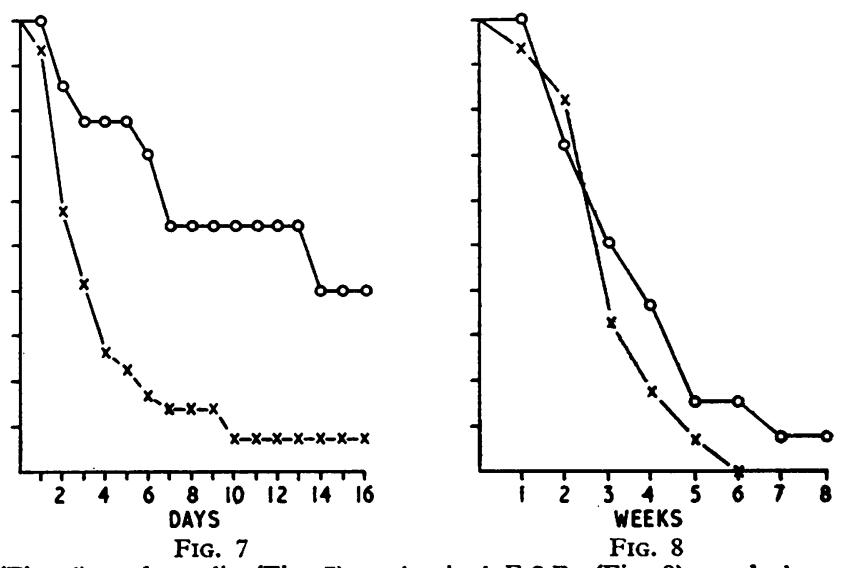

\section{Fibrinogen Studies}

Fletcher et al. (1952) and Welsh et al. (1961) have suggested that the plasma fibrinogen level is a more accurate measure of tissue damage and disease activity than the E.S.R. For this reason we carried out serial fibrinogen estimations in 24 patients. The upper limit of normal by the method used was taken as $400 \mathrm{mg} . / 100 \mathrm{ml}$. Before treatment all patients had high fibrinogen levels, ranging from 439 to $914 \mathrm{mg} . / 100 \mathrm{ml}$, with a mean of $702 \mathrm{mg}$.

Of the 10 patients treated with aspirin, nine still had abnormal fibrinogen levels on the seventh day of treatment. A further three fell to normal during the second week of treatment, but at the 28th day of treatment the remaining six had continuing high fibrinogen levels. Two of these did not become normal until the tenth week and one remained abnormal until the fifteen week.

In the phenylbutazone group of 14 patients 9 still had high fibrinogen levels on the seventh day of treatment but only two remained elevated on the fourteenth day, and all were normal by the twenty-eighth day. These findings are illustrated in Fig. 9.

\section{Discussion}

Although the incidence of acute rheumatism has diminished in the last 20 years (Hitchens, 1956) it is still an important problem. Ieff (1956) estimated from compulsory notification figures that 4,000 to 5,000 new cases occur in schoolchildren in Great Britain each year. While there have been advances in the prevention of rheumatic fever, no notable improvement in its treatment has occurred. Steroid hormones and salicylates suppress the acute symptoms of the disease but often in an incomplete manner, and fresh manifestations of activity may arise during treatment (Joint Report, 1955). The therapeutic effects obtained in the chronic rheumatic diseases with phenylbutazone (Currie, 1952 ; Currie et al., 1953 ; Kuzell et al., 1953) led to its use in acute rheumatic fever, and a number of favourable reports appeared (Fleming and Will, 1953 ; Chaptal et al., 1956 ; Colson et al., 1956,; Ablard et al., 1957 ; Laplane et al.,

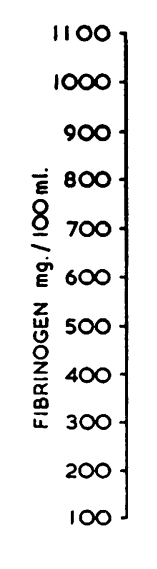

which had become normal in all cases by the end of the sixth week of treatment. In the aspirin group the E.S.R. remained raised in $9(22 \%)$ cases at that time. While seven of the cases treated with aspirin developed further acute manifestations during therapy, no recrudescence of activity was noted in the phenylbutazone group.

Reid and Sproull (1957) regard hyperfibrinogenaemia as an essential feature of rheumatic fever and consider the plasma fibrinogen concentration to be a reliable index of the course of the disease. An early return of the plasma fibrinogen to normal has been accepted as a good prognostic sign (Losner and Volk, 1956). It is interesting to note that our fibrinogen studies demonstrate a marked superiority of phenylbutazone in producing a return of plasma fibrinogen to normal levels. Whereas 6 of the 10 aspirin-treated cases still had raised fibrinogen levels on the twenty-eighth day of treatment, all 14 patients given phenylbutazone had normal plasma fibrinogens by that time.

It is often difficult to persuade a child to take a full daily dose of aspirin, and there is an appreciable incidence of toxic sideeffects during the first week of therapy. In the dosage used we have found phenylbutazone free from untoward side-effects. In particular there has been no clinical evidence of fluid retention, and we feel that the changes in E.S.R. and plasma fibrogen were due to an anti-inflammatory effect.

The results of this trial indicate that phenylbutazone controls the acute manifestations of rheumatic fever more rapidly and effectively than adequate doses of aspirin.
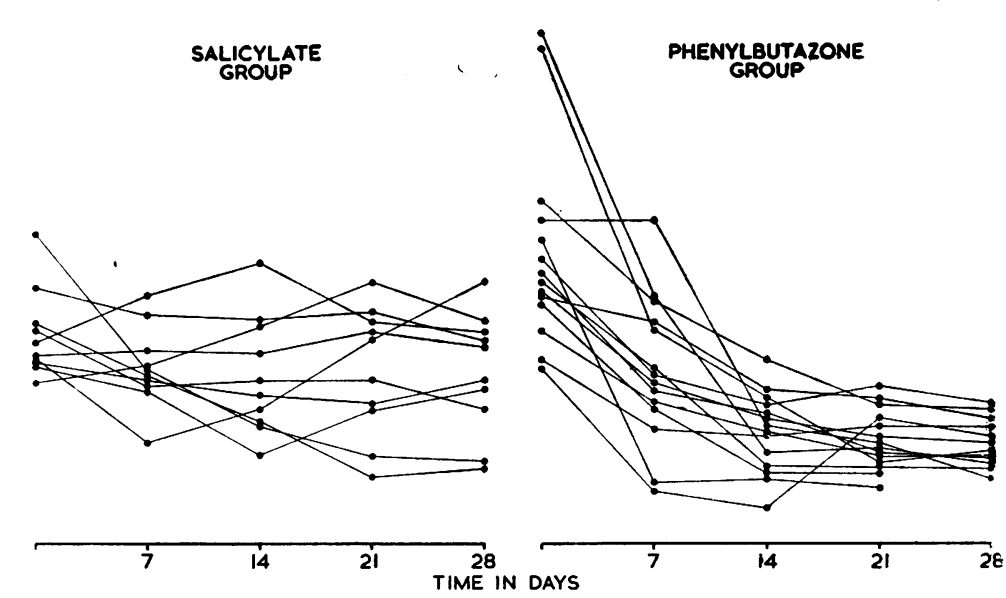

FIG. 9.-Response of plasma fibrinogen to treatment. 


\section{Summary}

A trial is described comparing the effects of aspirin and phenylbutazone in the treatment of acute rheumatic fever. So far as was possible alternate cases were treated with each drug, resulting in totals of 41 cases treated with aspirin and 47 with phenylbutazone. Detailed analysis of the two groups showed them to be comparable.

The rusults were assessed clinically by the time taken for relief of joint pain and swelling, and for resolution of fever and tachycardia. Frequent estimations of the E.S.R. were made in all cases, and in 24 patients serial plasma fibrinogen estimations were carried out in addition.

The clinical symptoms were relieved earlier and the E.S.R. showed a more rapid return to normal in the phenylbutazone group. Phenylbutazone also produced a more rapid return of the plasma fibrinogen to normal levels.

Although acute symptoms recurred during treatment in seven of the cases on aspirin, there was no evidence of recrudescence in the phenylbutazone group.
REFERENCES

Ablard, G., Larcan, A., and Welfringer, A. (1957). Un. méd. Can., 86, 932 .

Begg, T. B., Kerr, J. W., and Knowles, B. R. (1962). Brit. med. f., 2,

Chaptal, J., Jean, R., and Campo, C. (1956). Sem. Hôp. Paris, 32, 1175

Colson, J. A., Uters, M., and Haberer, Ch. (1956). Bull. Soc. Méd. milit. franç., 50, 166 .

Currie. J. P. (1952). Lancet, 2, 15.

- Peebles Brown, R. A., and Will, G. (1953). Ann. rheum. Dis., 12, 88.

Fleming, J., and Will, G. (1953). Ibid., 12, 95.

Fletcher, A. A., Dauphinee, J. A., and Ogryzlo, M. A. (1952). f. clin. Invest., 31, 561 .

Hitchens, R. A. N. (1956). Ann. rheum. Dis., 15, 160.

Joint Report by M.R.C. and American Heart Association (1955). Brit.

med. F., 1, 555.

Jones, T. D. (1944). 7. Amer. med. Ass., 126, 481. Wuzell, W. C., Schaffarzick, R. W., Naugler, W. E., Gaudin, G., and Mankle, E. A. (1953). Arch. intern. Med., 92, 646.

Laplane, R., Debray, P., Salbreux, R., and Polonovski, C. (1957). Bull. Soc. Méd. Paris, 73, 302

Leff, S. (1956). Ann. rheum. Dis., 15, 33.

Losner, S., and Volk, B.W. (1956). Amer. f. med. Sci., 232, 276.

Reid J. and Sproull, D. H. (1957). Brit. med. F., 1, 1089.

Stirland, R. M. (1956). Lancet, 1, 672. 241, 207

Will, G. (1958). Rheumatologie, 10, 103.

\title{
Neonatal Myasthenia Gravis
}

\author{
GERALD M. STERN,* M.B., M.R.C.P.; JUDITH M. HALL, † M.B., M.R.C.P.ED., D.C.H. \\ DEREK C. ROBINSON, $†$ B.M., M.R.C.P.
}

Brit. med. F., 1964, 2, 284-286

Strickroot et al. (1942) described the case of a mother with myasthenia gravis whose newborn child developed signs of generalized weakness on the third day of life and died on the seventh day from respiratory failure. Since then 34 further cases of neonatal myasthenia gravis have been described in the literature. The potential gravity of the disorder, and its possible bearing on the aetiology of myasthenia gravis, justify reporting the clinical and serological features of two further cases.

\section{Case 1}

In 1956, when aged 23, the mother of this case had complained of double vision and drooping of the lids, which responded dramatically to neostigmine. Two years later she developed weakness of the trunk and proximal limb muscles. The weakness fluctuated in severity, but she was able to remain at work while taking up to $300 \mathrm{mg}$. of pyridostigmine daily. In 1960 she began to complain of occasional aching discomfort and swelling in the joints of both hands, which responded to salicylates. Special investigations revealed no abnormality. A radiograph of the chest showed no evidence of thymic enlargement, plasma proteins and E.S.R. were normal, and lupus erythematosus cells were not seen in her peripheral blood.

She was pregnant for the first time in February 1962 and became weaker during the last three months of her pregnancy. She was noted to have a variable asymmetrical ptosis, impaired ocular movements with diplopia, moderate generalized weakness of the trunk and shoulder-girdle muscles, and brisk tendon reflexes. She had swelling of the interphalangeal joints of both hands, moist palms, and ulnar deviation of her right wrist. Normal foetal movements

\footnotetext{
- Department of Neurology, London Hospital. Present address : Department of Neuroiogy, the Royal Victoria Infirmary, Newcastle upon Tyne.

+ Department of Paediatrics, London Hospital.
}

were present throughout her pregnancy, and in the latter part she required $420 \mathrm{mg}$. of pyridostigmine daily.

During labour she had regular strong uterine contractions, but became fatigued in the second stage and was delivered by forceps of a male infant weighing $7 \mathrm{lb} .8 \mathrm{oz}$. (3,400 g.) on 18 October 1962.

The infant appeared normal at birth, but when 24 hours old had an attack of hiccups, and excessive mucus was aspirated from the pharynx. Five hours later he was found to be hypotonic, with shallow respiratory excursions. His eyes were staring, he had a feeble cry and a drooping lower jaw, and corneal and suck reflexes were absent. Within 10 minutes he responded to $0.25 \mathrm{mg}$. of intramuscular neostigmine and was found to need $0.3 \mathrm{mg}$. intramuscularly three-hourly, it being given with atropine to counteract the muscarine effects of the neostigmine. Despite this regimen his suck reflex remained weak, his lower jaw sagged occasionally, and he required to be tube-fed for the next two weeks. During the first week of life he had several severe cyanotic attacks. Attempts to wean him off neostigmine were made on the 18th, 22nd, 33rd, and 42 nd days, but each occasion was followed by a relapse, with recurrence of his original symptoms and signs, which responded to further neostigmine. Treatment was finally stopped on the 47th day without ill effects, and he subsequently appeared to be a normal infant. He was last seen when 1 year old.

There were no antibodies to normal human muscle in the mother's serum, using an indirect immunofluorescent technique. Complement-fixation tests on the mother's serum and the baby's serum on the third day of life, using human muscle, brain, liver, thyroid, and placenta as antigens, were all negative. The latex test was negative in both mother and child. Antinuclear factor was present in the serum of both.

\section{Case 2}

In 1958 , at the age of 23 and during the fourth month of her first pregnancy, this mother developed generalized weakness, so that climbing. stairs and combing her hair became an effort ; a few weeks later she complained of diplopia. Her symptoms persisted through- 